\title{
Hemodynamic Dimension Trend between Non Conversion and Conversion Lumbar Epidural Anesthesia to General Anesthesia Explored using Pulse Oximeter Technology
}

\author{
Zafri Bin Yusoff', Ir. Dr Ahmad Faizul Bin Shamsudin² \\ ${ }^{1}$ Institut Latihan Kementerian Kesihatan Malaysia Sultan Azlan Shah, Perak Malaysia \\ ${ }^{2}$ Associate Professor, Universiti Sultan Azlan Shah (USAS), Bukit Chandan Kuala Kangsar, Perak Darul Ridzuan, Malaysia
}

\begin{abstract}
How to cite this paper: Zafri Bin Yusoff | Ir. Dr Ahmad Faizul Bin Shamsudin "Hemodynamic Dimension Trend between Non Conversion and Conversion Lumbar Epidural Anesthesia to General Anesthesia Explored using Pulse Oximeter Technology" Published in International Journal of Trend in Scientific Research and Development (ijtsrd), ISSN: 24566470, Volume-3 | Issue-3, April 2019, pp.317-325, URL: http://www.ijtsrd.co $\mathrm{m} /$ papers/ijtsrd217 66.pdf

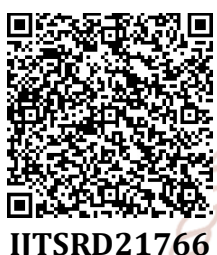

Copyright (c) 2019 by author(s) and International Journal of Trend in Scientific Research and Development Journal. This is an Open Access article distributed under the terms of the Creative Commons

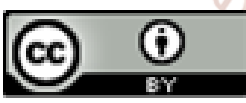
Attribution License (CC BY 4.0) (http://creativecommons.org/licenses/ by/4.0)

\section{ABSTRACT}

\section{Background}

Lumbar epidural anesthesia was considered to be the gold standard in anesthesia practice. It caused some form sympathetic blockade and changed baseline peripheral vascular tone including some dynamic changes. However, failure of epidural anesthesia was a clinical problem together with difficult to predict failure based on clinical parameter and hemodynamic changes

\section{Methods}

Parturient undergoing lower segment caesarean section LSCS surgery under epidural anesthesia enrolled in this mono centric study. Parturient were in the range of age 16 - 45 years old with ASA 1, II and II involved in the study The total of 160 parturient (respondents) planned for elective and emergency lower segment caesarean section LSCS surgery obtained from Yamane formula $\mathrm{n}=\mathrm{N}$ / $\left(1+\mathrm{Ne}^{2}\right)$ calculation with the Universal Convenience Sampling. Clinical observational and interventional methods were applied using a formatted checklist. Visual analogue pain scores VAPS, Bromage scale and perfusion index PI were used as instrument to assess lumbar epidural anesthesia blockade. After the administration of hyperbaric anesthetic drug into epidural space, hemodynamic changes of perfusion index PI were recorded every five minutes. Simultaneously, somatosensory, visual analogue pain scores VAPS, Bromage scale were assessed. Statistical analyses with SPSS version 24 were performed using Independent $\mathrm{T}$ - Test, ANOVA and Bivariate analysis for numerical variable. Levene's Test for equality of variances assumption was used to check for homogeneity of numerical variables.

\section{Recommendation}

Future direction Technology advances should be used as way to predict epidural failure such as Transcutaneous Electrical Nerve Stimulation (TENS). Ultrasound imaging of the spine could be proposed to facilitate identification of the epidural space and predict difficult spine identification, especially in women with abnormal lumbosacral anatomy (scoliosis) and those who were obese.

\section{Results}

The hemodynamic dimension of initial blood pressure did not influence the trend of perfusion index PI for both groups of non-conversion and conversion of lumbar epidural anesthesia. These were elaborated through (Systolic: $r=-$ $0.01, p>0.05$ ), (Diastolic: $r=-0.70, p>0.05$ ). Similarly the initial pulse rate as element of hemodynamic did not influence the trend of perfusion index as $r=-0.10, p>0.05$. It was a novelty finding that initial pulse rate influenced the hemodynamic trend of initial blood pressure (Systolic: $r=$ $0.31, p>0.05$ ), (Diastolic: $r=0.44, p<0.05$ ). Also, there was a significant changed in the mean perfusion index with the rate of $115.4 \%$ increased of perfusion index PI for nonconversion group in 20 minutes duration. The perfusion index PI for non-conversion group increased with the rate of $80.0 \%$ in 20 minutes duration. Hemodynamic dimension especially referring to perfusion index PI $(\mathrm{p}<0.05)$ at parameter value of base line $3.99 \pm 0.44$ contributed to the lumbar epidural anesthesia failure. Our overall lumbar epidural anesthesia failure rate was $3.8 \%$ in this study.

\section{Conclusions}

Perfusion index PI considered a reliable and simpler hemodynamic assessment for lumbar epidural anesthesia failure for parturient undergoing lower segment caesarean section LSCS surgery. Perhaps new heuristics in new Transition Policy Anesthesia Analysis TAPA could be developed for addressing more holistic in determination of lumbar epidural anesthesia failure among parturient undergoing lower segment caesarean section LSCS surgery in terms of hemodynamic dimension. 
Keywords: Pulse Oximeter, Perfusion Value Index SpO2, Epidural Failure, Lower Segment Caesarean Section LSCS, Lumbar Epidural Anaesthesia

\section{INTRODUCTION}

There were some forms of curiosity about lumbar epidural anesthesia occasionally did not work which considered as lumbar epidural anesthesia failure. The incidence of epidural anesthesia failure needed to be addressed as parturient expected a very satisfactory analgesia in the contexts of lower segment caesarean section LSCS surgery. Pain was considered the oldest medical problem and the universal physical affliction of mankind. Yet not much understanding had been explored to understand especially in physiological contexts. A question could be thrown here why epidural anesthesia did not work occasionally. Pain was a subjective feeling that could affect physiological wellbeingand emotional experience. It had been addressed as a factor to stimulate the sympathetic nerve system causing to increase Oxygen $\mathrm{O}_{2}$ consumption in human body.

Lumbar epidural anesthesia (epidural blockade) was used very mostly for procedures involving lower abdomen especially for lower segment caesarean section LSCS surgery. The belief system that initiation of epidural blockade (epidural anesthesia) would result pain free and consciousness level maintained. Previous authors studied the various reasons the possibility of epidural anesthesia converted to general anesthesia. For an example, Hermanides et al (2012) came out with few reasons why epidural anesthesia failure occurred. They listed reasons for epidural anesthesia failure occurred including incorrect primary placement, secondary migration of a catheter after correct placement, and suboptimal dosing of local anesthetic drugs but they did not mention anything about hemodynamic changes that might affect lumbar epidural anesthesia.

Something came into our mind why epidural anesthesia had the tendency to be converted into general anesthesia. Perhaps the current report of epidural anesthesia failure rates for caesarean section delivery should be re examined. The current review was not sufficiently summarizes whether technical factors known to influence epidural anesthesia failure. On the other hand pharmacologic factor gave a reason why epidural anesthesia converted into general anesthesia. A report by Robert et al (2009) emphasized primary epidural anesthetics for elective cesarean delivery had a failure rate of $0.21 \%$ which considered very nominal.

Shin et al (2016) highlighted in quite detail about epidural anesthesia pertaining to hemodynamic dimension. They gave their opinion that efficacy of regional anesthesia in women undergoing lower segment caesarean section LSCS. They discussed about hemodynamic changes and stability including a statement converting into general anaesthesia after failure of epidural anesthesia was $5 \%$. Therefore, a preparation to induce general anesthesia if epidural anesthesia failure occurred considered mandatory. The question here was, did hemodynamic dimension could be considered or as predictor for epidural anesthesia failure?

At the junction there was no clear evidence about hemodynamic changes or instability could affect the successful rate of epidural anesthesia. For the clinical context, there was no globally-accepted definition of epidural anesthesia failure: this leaded to wide differences in reported failure rates.

As such, data analysis by Katircioglu et al describing the $0.35 \%$ failure rate of epidural anesthesia for lower segment cesarean section LSCS surgery. Whereas, Halpern et al (2009) stated ( $n=21,4.1 \%)$ parturient required general anesthesia GA after epidural anesthesia administration. Sen (2016) revealed minimizing hemodynamic changes resulting from sympathetic autonomic blockade (epidural anesthesia) through a case report of Epidural Anesthesia for lower segment caesarean section LSCS surgery among parturient with severe pulmonary hypertension. However, he did not state whether hemodynamic changes could be considered as predictor for epidural failure.

In spite of some percentage of epidural anesthesia failure especially among parturient undergoing lower segment caesarean section, the real caused of lumbar epidural anesthesia failure still hidden. It was so difficult to relate with hemodynamic dimension as causes more towards technical and pharmacological problems. It was also related to the believed that incidence of lumbar epidural failure depended on the institution setting and the level of training duration of anesthetist performing it. Furthermore, it was claimed that lower segment caesarean section LSCS surgery was one of the most common surgical procedure globally. As claimed by Wang (2017) lower segment caesarean section LSCS rates had risen in China within the past 25 years, with specific statement driven by non-medical factors and maternal requests. Universally too, it was so rare to find issue about hemodynamic dimension as predictor to indicate lumbar epidural anesthesia failure.

\section{Material and Methods}

This study was conducted in Labor Room Hospital Raja Permaisuri Bainun to evaluate the hemodynamic dimension as an early detection of epidural anesthesia failure for parturient mothers scheduled for lower segment caesarean section LSCS surgery. Parturient mothers planned for elective and emergency LSCS and undergoing epidural anesthesia chosen as samples of this study. The sample size was calculated based on Yamane formula $\mathrm{n}=\mathrm{N} /\left(1+\mathrm{Ne}^{2}\right)$ Where $\mathrm{n}=$ corrected sample size, $\mathrm{N}=$ population size, and $\mathrm{e}=$ margin of error (0.05) based on the research condition. The total population of parturient undergoing lower segment caesarean section LSCS during the study period was 271 parturient. Hence the required samples size were 160 parturient calculated using Yamane formula. Lower segment caesarean section LSCS surgery would not been begun until loss of sensation to ethyl chloride spray/pin prick/fine touch with cotton achieved bilaterally to maximum level T7. The parturient would be accepted for this the study if the block did not reach the level T7 within 30 min or with an additional study drug injected and 45 min after the 3rd dose. For this perspective, both successful and epidural anesthesia failure groups were accepted for this study for making a comparative analysis. World Federation of Societies of Anesthesiologists (2001) recommended that height of block suitability for LSCS surgery at T6 - T7. Motor block been assessed bilaterally using the modified Bromage scale: $1=$ no paralysis (full flexion of hip, knee and foot), $2=$ unable to flex hip (able to flex knee and ankle), 3 = unable to flex knee (able to flex foot only), $4=$ unable to flex hip, knee or ankle joint. Motor block assessments will not be made during LSCS surgery. 
Sampling of the study was done through wide range of age group of all parturient mothers undergoing epidural anesthesia. We as researchers used combination of clinical observational and interventional methods for parturient mothers undergoing for LSCS and examined achievable of satisfactory level of epidural anesthesia after epidural puncture plus insertion of Tuohy epidural needle and catheter including the injection of drugs used. Parturient mothers were in sitting position and asked to arch their back and remain still while sitting up during insertion of epidural needle through lumbar space. The Universal Convenience Sampling was used to gather a valid representing of the total populations within the time frame of collecting data. The total population of parturient mothers undergone LSCS were 271 within the period of $1^{\text {st }}$ January to $12^{\text {th }}$ July 2017.

\section{Instrumentation}

A checking list as an observation proforma for lower segment caesarean section LSCS surgery epidural anesthesia was used to collect the data in exploring factors contribute to the satisfactory level of epidural anesthesia for parturient mothers planned for elective and emergency LSCS. As clinical practice, a pulse oximetry technology also been used as continuous monitoring plus as predictor to measure values of peripheral capillary oxygen saturation $\mathrm{SpO}_{2}$ for the epidural anesthesia effectiveness. The perfusion index PI was monitored and recorded at $0,5,10,15$, and $20 \mathrm{~min}$ intervals after epidural anesthesia commenced. For intra operative monitoring non-invasive blood pressure and mean arterial pressure MAP measurements were done simultaneously with perfusion index PI observation.The initial cardiac output $\mathrm{CO}$ was computed using the simple calculation $\mathrm{CO}=$ Stroke Volume (Normally, $70 \mathrm{ml} /$ beat $)$.) * The Initial Heart Rate.

For additional information the oximetry sensor was attached to the first finger of the left hand on the side where procedure of LSCS surgery was initiated at the right side of parturient. The sensor was connected in order to obtain baseline perfusion index PI, pulse and $\mathrm{SpO} 2$ values for peripheral capillary Qxygen saturation.

\section{Statistics}

Statistical analyses were performed using SPSS $®$ version 24.0. Data that collected and computed were represented as mean ( \pm standard deviation) for quantitative variables and percentages for qualitative variables. Distribution of perfusion index PI was subjected to normality test $(\mathrm{P}<0.05)$. The point-biserial correlations were used for examining the association between mean perfusion index PI and epidural failure incidence/successful epidural anesthesia using independent $\mathrm{T}$ Test. Levene's test was used to check homogeneity of numerical variables

\section{Results and Discussion}

A total of hundred and sixty $(\mathrm{n}=160)$ parturient involved in this study. This was from $\mathrm{N}=271$ of the total population of parturient undergone epidural anesthesia during the period of data collection 21st January till 10 of July 2017 . The mean age of parturient participated in this study was 28.03 years with a standard deviation of \pm 5.48 . The minimum and maximum ages were 16 and 45 years respectively. Parturient with non-conversion of lumbar epidural anesthesia to general anesthesia reported to have mean age of $27.96 \pm 5.47$ where as those with conversion to general anesthesia was $29.83 \pm 6.11$ (Table 1 ).

Table 1: Comparative Analysis of Mean Age

\begin{tabular}{|c|c|c|c|c|c|}
\hline \multicolumn{6}{|c|}{ Group Statistics - Independent Sample T Test } \\
\hline & $\begin{array}{c}\text { GA } \\
\text { Conversion }\end{array}$ & $\mathrm{n}$ & Mean & $\begin{array}{c}\text { Std. } \\
\text { Deviation }\end{array}$ & $\begin{array}{c}\text { P } \\
\text { value }\end{array}$ \\
\hline Age & YES & 6 & 29.83 & 6.11 & 0.41 \\
\cline { 2 - 5 } & NO & 154 & 27.96 & 5.47 & \\
\hline
\end{tabular}

At this particular incident, it was observed also that mean parity was $0.86 \pm 1.22$. On the other hand, successful epidural group had mean parity of $0.76 \pm 1.17$ and epidural conversion group to general anesthesia was $1.00 \pm 1.10$. There was no concrete reference data in analyzing the effect of parity on the successful or epidural anesthesia failure. Muppuri et al (2012) studied for factors of risk potential independent epidurals failure among 502 parturient for labor. In their study they indicated that $\mathrm{n}=171(34.1 \%)$ were nulliparous and $n=331(65.9 \%)$ were primiparous. It was not so convincing whether parity affected the efficacious epidural anesthesia. For this particular aspect, we found our respondents $n=89$ (55.6) were nulliparous, $n=32(20.0 \%)$ were primiparous and $n=39,(24.4 \%)$ were multiparous (Refer Figure 1).

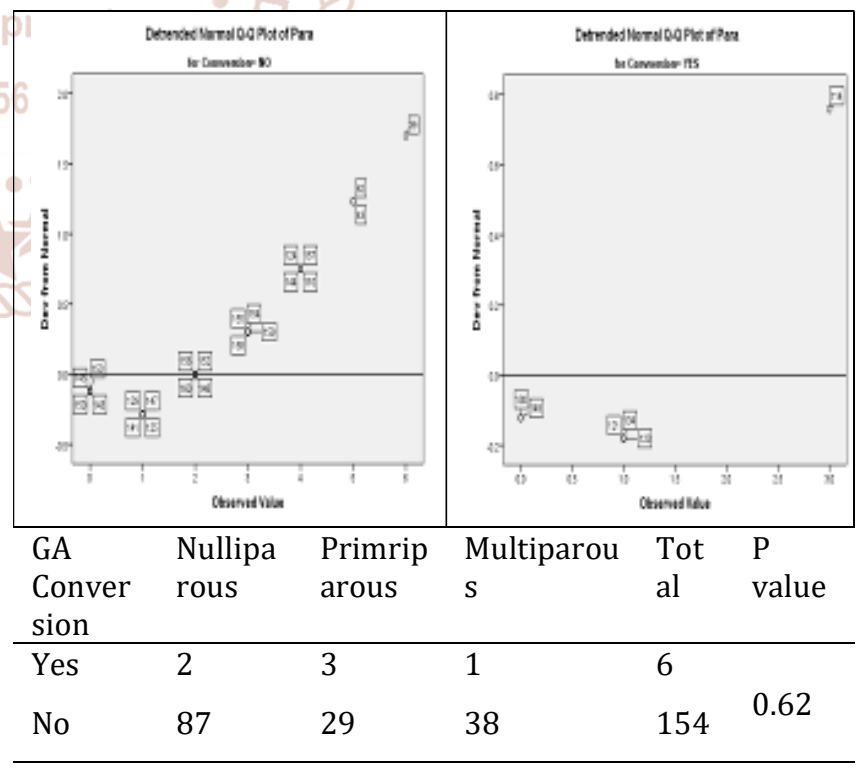


International Journal of Trend in Scientific Research and Development (IJTSRD) @ www.ijtsrd.com eISSN: 2456-6470

Figure 1: Comparative Analysis of Parity for Non Conversion and Conversion of Lumbar Epidural Anesthesia
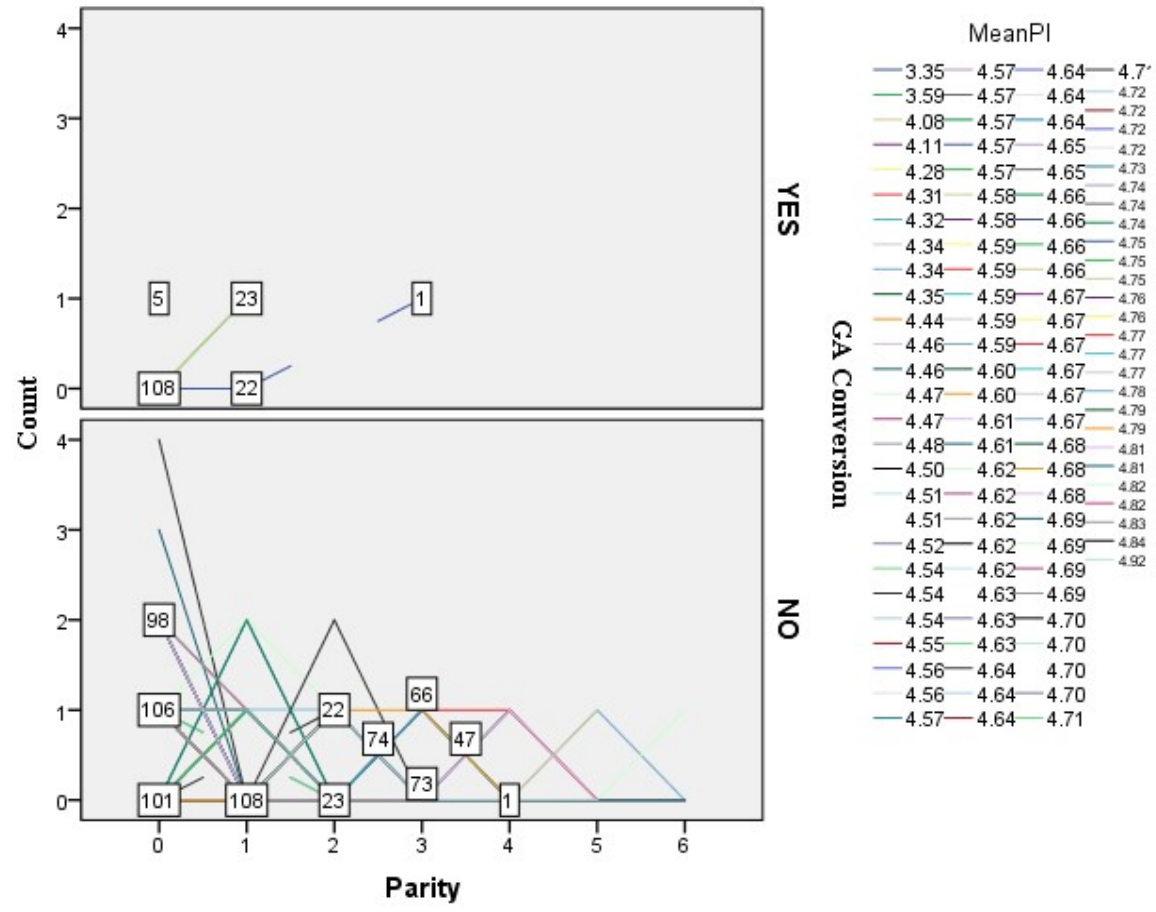

Figure 2: The Perfusion Index PI Trend between Non-Conversion and Conversion Group with Reference to Parity

As illustrated in Figure 2, we noticed the highest mean of perfusion index trend among nulliparous parturient for the nonconversion group of lumbar epidural anesthesia. At the same time there was negative correlation $(p>0.05, p=0.62)$ meaning that parity did not influence the effectiveness of lumbar epidural anesthesia among parturient.

The mean epidural needle inserted was $4.45 \pm 0.75 \mathrm{~cm}$ with minimum of 4.00 and maximum of $10.00 \mathrm{~cm}$ for hundred and sixty parturient involved in this study (Table 2). A very strange phenomenon found in this study regarding the longest epidural needle insertion was in the non-conversion group (10.0 cm depth) as displayed in figure 3 below. We tested the homogeneity variances of catheter needle insertion between the two groups and found no significant difference as Levene statistic with $p$ value 0.70 whereby $\mathrm{p}>0.05$. At the same time we confirmed with ANOVA and the $p$ value $0.87, \mathrm{p}>0.05$. The mean epidural needle insertion for non-conversion group was $4.45 \pm 0.76$ and for epidural conversion group $4.50 \pm 0.45 \mathrm{~cm}$. The difference of mean epidural needle insertion was $1.11 \%$ ( $0.05 \mathrm{~cm}$ difference). Shiroyama et. al (2003) concluded that the distance of epidural needle from skin to epidural space for most Japanese parturient women were $3.00-4.00 \mathrm{~cm}$ at the L1-L2 inter space. In our study we did not attempt L1-L2 inter space but mostly at L3 - L4 inter space ( $n=87,54.4 \%)$ with mean depth of $4.49 \pm 0.92$ in $\mathrm{cm}$.

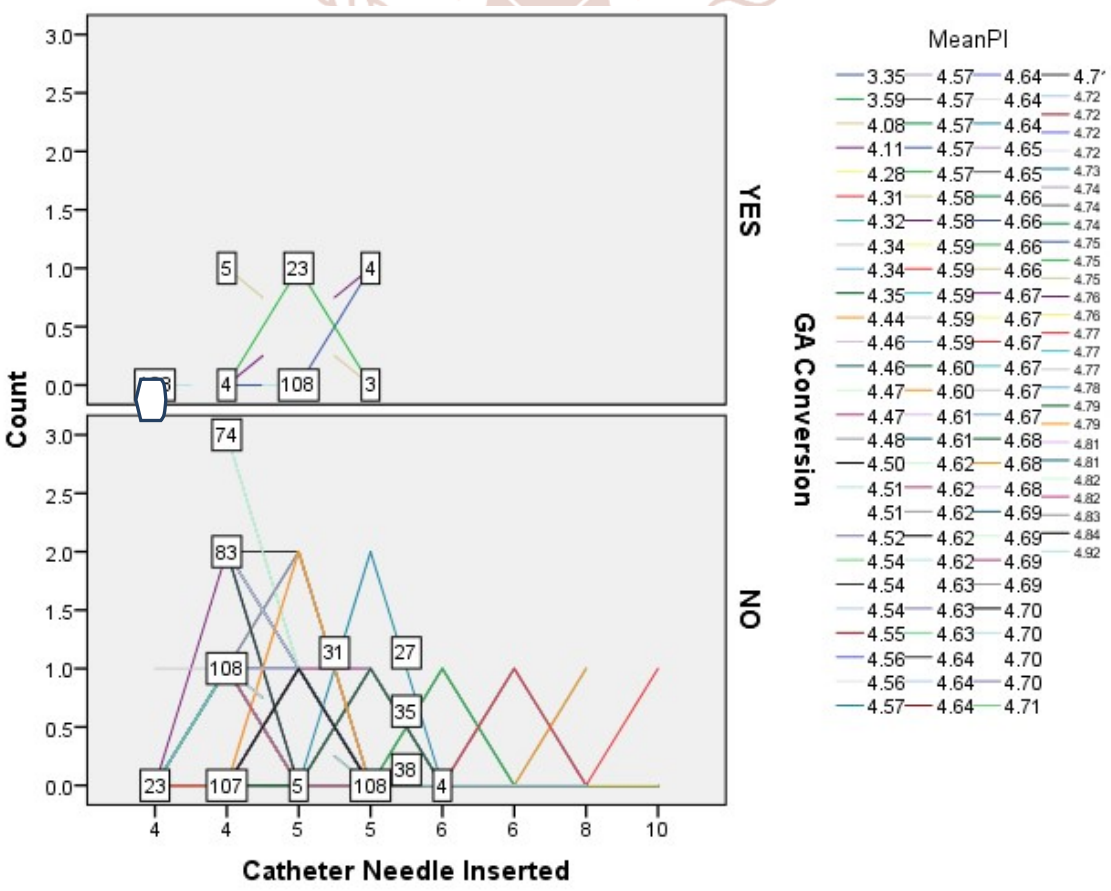

Figure 3: The Perfusion Index PI Trend between Non Conversion and Conversion Group with Reference to Skin-Epidural Space Distance (Depth) 
International Journal of Trend in Scientific Research and Development (IJTSRD) @ www.ijtsrd.com eISSN: 2456-6470

Table 2: Homogeneity Test and Anova Statistic

\begin{tabular}{|c|c|c|c|c|c|c|}
\hline \multicolumn{2}{|c|}{ Levene Statistic } & \multicolumn{3}{c|}{ Sig. } \\
\hline \multicolumn{3}{|c|}{ ANOVA } & 0.15 & \multicolumn{3}{c|}{0.70} \\
\hline Catheter Needle Inserted & Sum of Squares & df & Mean Square & F & Sig. \\
\hline \multicolumn{2}{|c|}{} & .02 & 1 & .02 & .03 & .87 \\
\hline Catheter Needle Inserted & Between Groups & 2.50 & 1 & 2.50 & 152.25 & .00 \\
\hline MeanPI & Between Groups & & 150 &
\end{tabular}

Mean maternal initial Blood Pressure Systolic (S)) / Diastolic (D) at the level of 131.53 (S) / $80.25 \mathrm{mmHg}$ (D) \pm 16.55 (S) / 9.95 mmHg (D) for the non-conversion lumbar epidural anesthesia LEAS group. While the mean maternal initial Blood Pressure Systolic (S)) / Diastolic (D) for the lumbar epidural anesthesia conversion LEAF group that needed conversion to general anesthesia was recorded as 134.17 (S) / 84.83 (D) \pm 10.48 (S) / 9.96 (D) \pm 10.48 (S) / 9.96 (D) with $p$ value $=0.70$ (Systolic) $/ p$ value $=0.27$ (Diastolic) as seen from figure 4. The Hemodynamic dimension in the context of initial noninvasive blood pressure was very suitable for both lumbar epidural anesthesia and general anesthesia.

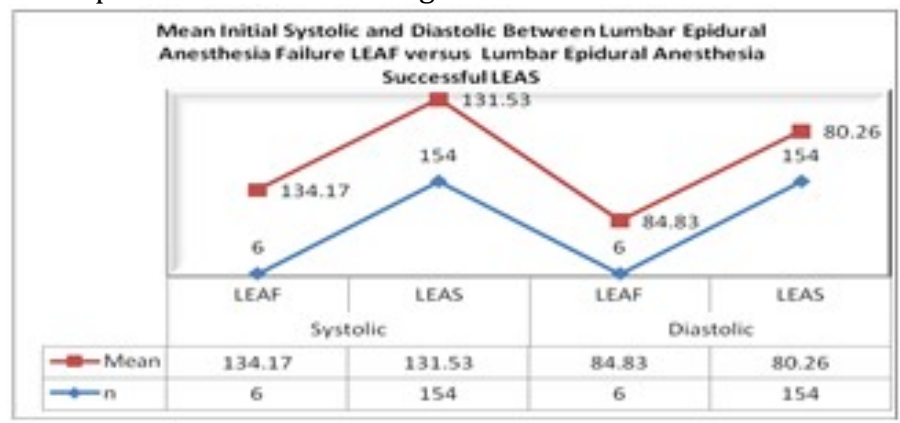

Figure 4: The Pattern of Systolic and Diastolic with Reference to Non-Conversion \& Conversion Groups

We analyzed the trend of perfusion index PI with reference to Systolic, Diastolic and initial pulse rate. Obviously we could note that Systolic $(r=-0.01, p>0.05)$, Diastolic $(r=-0.7, p>0.05)$ and initial pulse rate $(r=-0.10, p>0.05)$ proven negative correlation with perfusion index PI values (Refer Figure 5 \& Table 3). But it was to be a positive correlation between initial pulse rate and Systolic $(r=0.31, \mathrm{p}<0.05) \&$ Diastolic $(\mathrm{r}=0.44, p<0.05)$ values as emerged in Table 3 . We also noticed some form of positive correlation between Systolic and Diastolic with the interpretation that Systolic influenced hemodynamic changes for Diastolic dimension (Table 3).

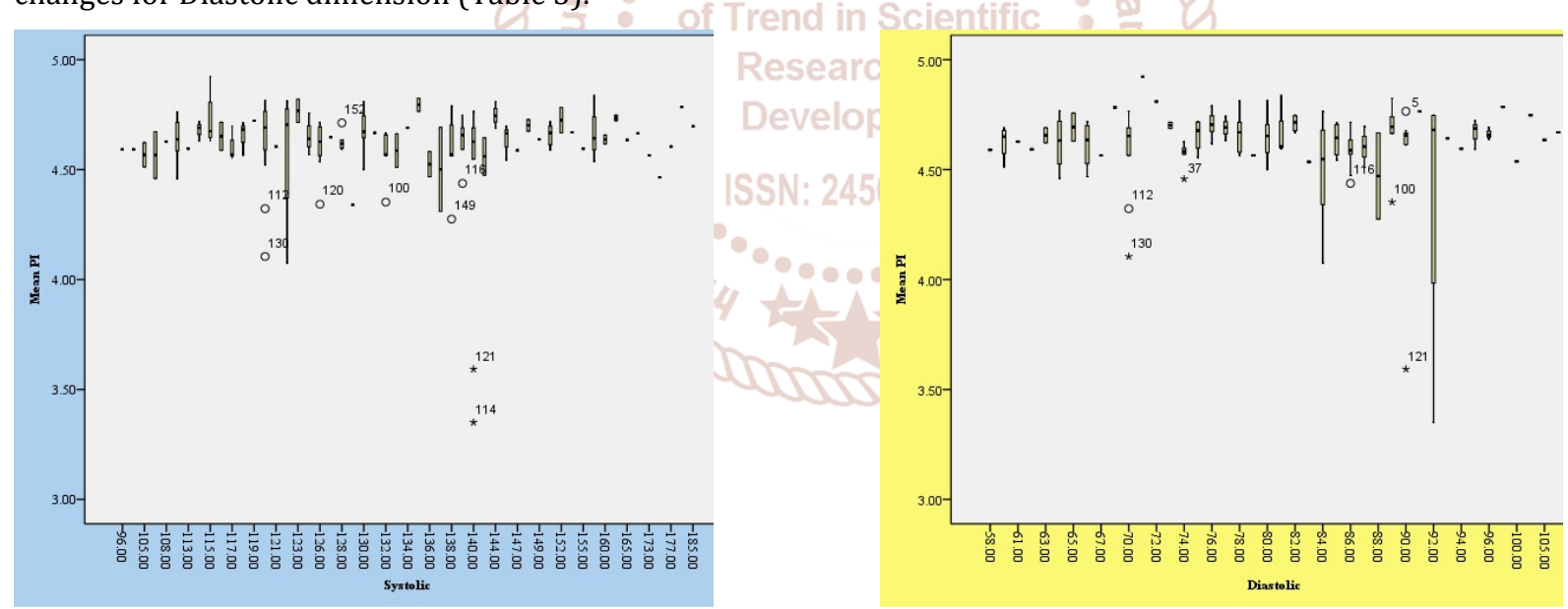

Figure 5: The Trend of Perfusion Index PI in Relation to Systolic and Diastolic Blood Pressure

Table 3: The Interaction of Mean Perfusion Index PI with Systolic, Diastolic and Initial Base Pulse Rate

\begin{tabular}{|c|c|c|c|c|c|}
\hline \multicolumn{6}{|c|}{ Correlations } \\
\hline & & Mean PI & Systolic & Diastolic & Initial Base Pulse Rate \\
\hline \multirow{3}{*}{ Mean PI } & Pearson Correlation & 1 & -.01 & -.07 & -.10 \\
\hline & Sig. (2-tailed) & & 0.93 & 0.41 & 0.20 \\
\hline & $\mathrm{n}$ & 160 & 160 & 160 & 160 \\
\hline \multirow{3}{*}{ Systolic } & Pearson Correlation & -.01 & 1 & $.61^{* *}$ & $.31^{* *}$ \\
\hline & Sig. (2-tailed) & 0.93 & & 0.00 & 0.00 \\
\hline & $\mathrm{n}$ & 160 & 160 & 160 & 160 \\
\hline \multirow{3}{*}{ Diastolic } & Pearson Correlation & -.07 & $.61^{* *}$ & 1 & $.44^{* *}$ \\
\hline & Sig. (2-tailed) & 0.41 & 0.00 & & 0.00 \\
\hline & $\mathrm{n}$ & 160 & 160 & 160 & 160 \\
\hline \multirow{3}{*}{ Initial Base Pulse Rate } & Pearson Correlation & -.10 & $.31^{* *}$ & $.44^{* *}$ & 1 \\
\hline & Sig. (2-tailed) & 0.20 & 0.00 & 0.00 & \\
\hline & $\mathrm{n}$ & 160 & 160 & 160 & 160 \\
\hline & ation is & ant at & $0.05 \mathrm{le}$ & 2-tailed) & \\
\hline
\end{tabular}


We also analyzed for the purpose of investigation was whether any relationship of interaction between mean arterial pressure MAP with mean perfusion index PI for the two group. The Pearson correlation coefficient $(r)$ was -0.04 and $p$ value $0.59, p>$ 0.05 which considered negative relation whereby mean perfusion index PI did not influence the reading of Mean arterial pressure MAP as displayed in Figure 6.

\begin{tabular}{|c|c|c|c|}
\hline \multicolumn{4}{|c|}{ Correlations } \\
\hline & & Mean PI & MAP \\
\hline \multirow{3}{*}{ Mean PI } & Pearson Correlation & 1 & -0.04 \\
\hline & Sig. (2-tailed) & & 0.59 \\
\hline & $\mathrm{n}$ & 160 & 160 \\
\hline
\end{tabular}

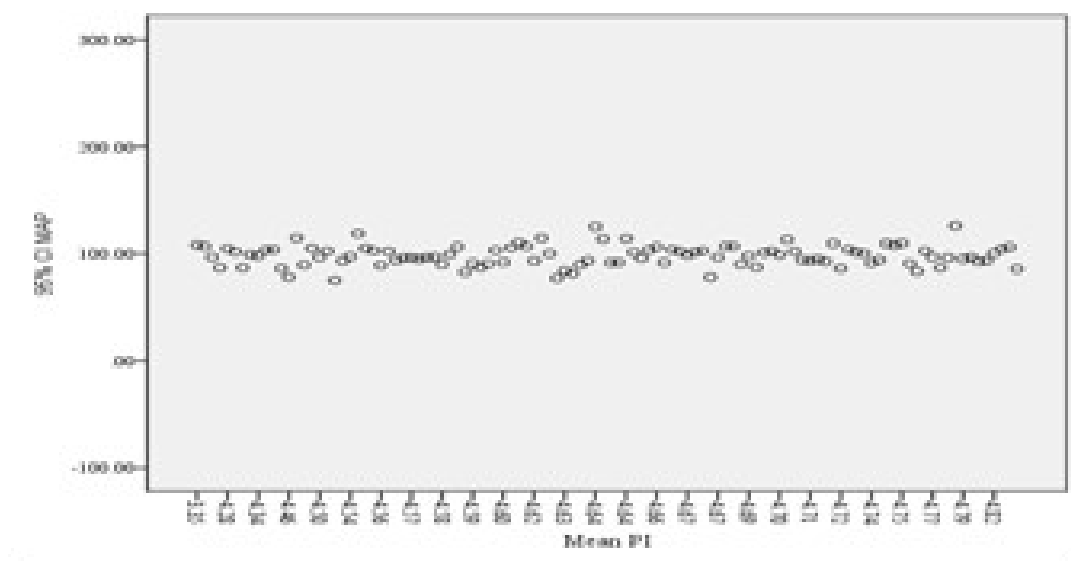

Figure 6: The Interaction of Mean Arterial Pressure MAP and Mean Perfusion Index PI

At the same time, we found mean arterial pressure had no relationship to the occurrence of efficacy of lumbar epidural anesthesia among parturient undergoing lower segment caesarean section LSCS surgery. We also would like to express that lumbar epidural anesthesia conversion group generally had higher mean arterial pressure MAP (101.28 \pm 8.18 ) compared to non- conversion group (97.35 \pm 10.92$)$. Statistically no significant difference in term of mean arterial Pressure as $t(158)=0.87$, $p=0.39, p>0.05$ between the two groups and 3.92 mean difference was not really gapped.

Table 4: Lumbar Epidural Anesthesia Conversion and Non-Conversion Group in Relation to Mean Arterial Pressure MAP

\begin{tabular}{|c|c|c|c|c|c|c|c|c|}
\hline & GA Conversion & $\mathrm{n}$ & Mean & Std. Deviation & $\mathrm{t}$ & P value & $\mathrm{df}$ & Mean Difference \\
\hline \multirow{2}{*}{ MAP } & YES & 6 & 101.28 & SSI. 8.18 -647 & \multirow{2}{*}{0.87} & 0.39 & \multirow{2}{*}{158} & \multirow{2}{*}{3.92} \\
\cline { 2 - 10 } & $\mathrm{NO}$ & 154 & 97.35 & 10.92 & & & \\
\hline
\end{tabular}

The mean differences of cardiac output between the two groups were shown in Figure 7. The lowest recorded of cardiac output occurred in non-conversion group (5933.63 $\mathrm{ml} / \mathrm{min}$ ) and the highest ( $6113.33 \mathrm{ml} / \mathrm{min}$ ) occurred in conversion group. However, statistically no significant difference in term of mean arterial Pressure as $\mathrm{t}(158)=735.20, p=0.56, p>0.05$ between the two groups and 3.93 mean difference. At this particular aspect, $1000 \mathrm{ml}$ of isotonic normal saline infused as pre load and did not affect much on hemodynamic changes as mean difference of cardiac out was only $179.70 \mathrm{ml}$.

\begin{tabular}{|c|c|c|c|c|c|c|c|c|}
\hline & GA Conversion & $\mathrm{n}$ & Mean & Std. Deviation & $\mathrm{t}$ & P value & df & Mean Difference \\
\hline \multirow{2}{*}{ Cardiac Output CO } & YES & 6 & 6113.33 & \multirow{2}{*}{795.25} & \multirow{2}{*}{735.20} & \multirow{2}{*}{0.56} & \multirow{2}{*}{158} & \multirow{2}{*}{179.70} \\
\cline { 2 - 10 } & NO & 154 & 5933.63 & & \\
\hline
\end{tabular}

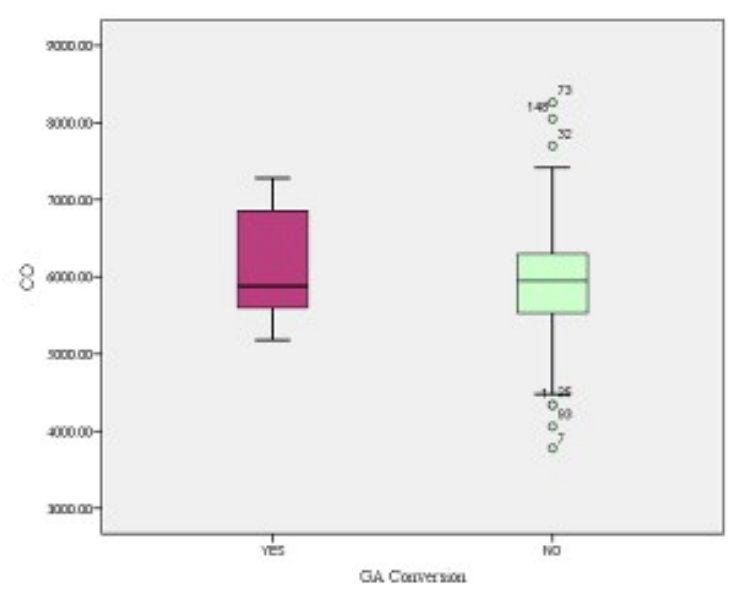

Figure 7: The Trend of Cardiac Output in Non-Conversion and Conversion Group of Lumbar Epidural anesthesia 
We found a justified positive correlation between non-conversion and conversion groups of lumbar epidural anesthesia with reference to baseline perfusion index PI. The t statistic was -12.34 and $p$ value $<0.05, \mathrm{P}=0.00$ at degree of freedom 158 . From the baseline of perfusion index PI during lumbar epidural anesthesia for lower segment caesarean section LSCS surgery demonstrated that the existing of gap by five minutes serial as emerging from figure 8 . The total $115.4 \%$ increased of perfusion index PI for non-conversion group whereas the total $91.8 \%$ increased of perfusion index PI for the conversion group for duration of 20 minutes. The mean gap of perfusion index was 0.47 which equivalent to 8.9\% (Figure 8).

\begin{tabular}{|l|c|c|c|c|c|c|}
\hline \multicolumn{7}{|c|}{ Group Statistics } \\
\hline & GA Conversion & $\mathrm{n}$ & Mean & Std. Deviation & t statistic (df) & $\mathrm{p}$ value \\
\hline \multirow{2}{*}{ Mean PI I } & YES & 6 & 3.99 & 0.44 & \multirow{2}{*}{$-12.34(158)$} & 0.00 \\
\cline { 2 - 7 } & NO & 154 & 4.65 & 0.10 & \\
\hline
\end{tabular}

\section{The Trend of Perfusion Index}

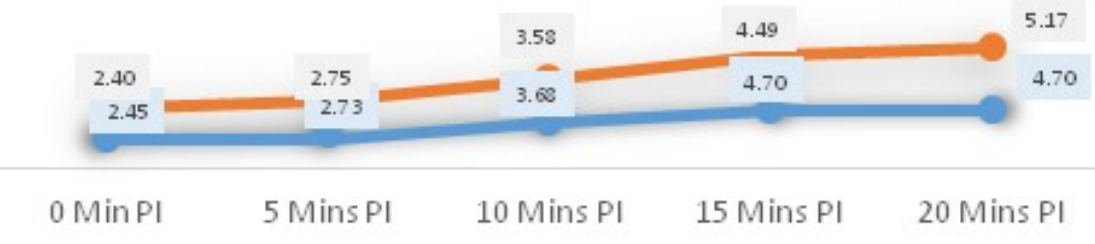

$\longrightarrow$ Group 1 -ConversionGroup Group 2 - NonC onversionGroup

Figure 8: Comparative Analysis of Perfusion Index Trend between Non-Conversion and Conversion Groups of Lumbar Epidural Anesthesia

We came out with the idea of exploring the interaction of cardiac output in reference to perfusion index PI. Our statistical analysis from bivariate correlation reflected the negative interaction as Pearson's $r=-0.10, p>0.05$. Therefore, cardiac output criterion did not influence the hemodynamic of perfusion index PI in this study (Figure 9).

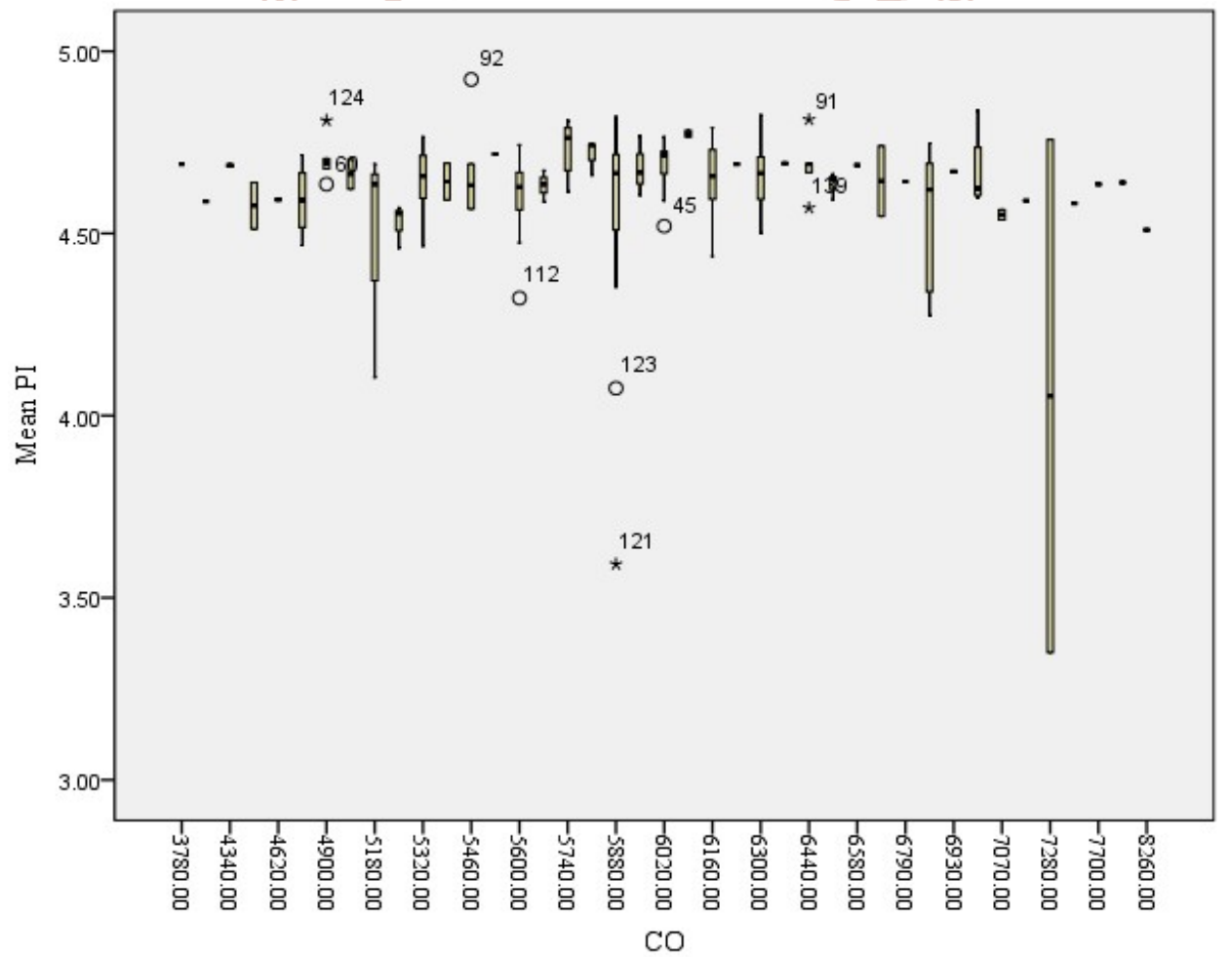

Figure 9: The Interaction of Cardiac Output with Reference to Perfusion Index PI ( $\mathrm{r}=-0.10, p>0.05)$

Our lumbar epidural anesthesia failure rate among parturient undergoing lower segment caesarean section LSCS surgery was only 3.8\%. A study done by Katircioglu et al (2008) claiming $0.35 \%$ failure rate of epidural anesthesia for lower segment cesarean section LSCS surgery which lower rate as compared to our result. 
International Journal of Trend in Scientific Research and Development (IJTSRD) @ www.ijtsrd.com eISSN: 2456-6470

\section{Summary}

Mean arterial pressure MAP and cardiac output did not affect the trend of perfusion index. But it was to be a positive correlation between initial pulse rate and Systolic $(r=0.31, \mathrm{p}$ $<0.05)$ \& Diastolic $(\mathrm{r}=0.44, p<0.05)$ values as emerged which could be interpreted that initial pulse rate influenced the Systolic and Diastolic trend. At the same time we also noticed some form of positive correlation between Systolic and Diastolic with the interpretation that Systolic influenced hemodynamic changes for Diastolic dimension. We found a justified positive correlation between non-conversion and conversion groups of lumbar epidural anesthesia with reference to baseline perfusion index PI. The t statistic was 12.34 and $p<0.05, \mathrm{P}=0.00$ at degree of freedom 158. Our lumbar epidural anesthesia failure rate among parturient undergoing lower segment caesarean section LSCS surgery was only $3.8 \%$. We concluded that it was a reliable indicator when mean base line $3.99 \pm 0.44$ of perfusion index contributed to the lumbar epidural anesthesia failure

\section{Recommendation}

Future direction technologic advances should be used as way to predict epidural failure. Transcutaneous Electrical Nerve Stimulation (TENS) should be used rather than using pin prick and fine touch with cotton for epidural effectiveness testing. There for we would like to propose perfusion index PI values derived from pulse oximeter to be used as a parameter in determination of epidural failure among parturient mothers undergoing lower segment caesarean section LSCS surgery.

\section{Limitation of the study}

We were not able to test the contractility of heart muscle fibers and strengths. The intrinsic ability analysis of the heart to contract independently of preload and afterload was beyond our capability. We were not able to justify the trend of perfusion index PI related to positive agents such as calcium/drug and acidosis or hyperkaliemia as negative agents. We could not have nerve stimulator something like Transcutaneous Electrical Nerve Stimulation (TENS) and ultrasound guided regional anesthesia techniques in order to reduce migration epidural needle during administration of anesthetic drugs for lower segment caesarean section LCSC surgery. It was supposed to reduce the risk of lumbar epidural anesthesia failure and increase the benefits of this kind of anesthesia (lumbar epidural anesthesia). The most concern was the perfusion index PI might affected with the element restraints on upper left extremity which might causing interference with blood flow.

\section{ACKNOWLEDGEMENTS}

This manuscript would have never been accomplished without the tireless guidance and mentorship of my supervisor

\section{Associate Professor DR. IR. AHMAD FAIZUL BIN} SHAMSUDIN

I would also like to appreciate my colleagues, for their great inspiration.

\section{REFERENCES}

[1] Aksoy, H (2015) Blood loss in elective cesarean section: is there a difference related to the type of anesthesia? A randomized prospective study Journal Turkey German Gynecology Association 2015; 16(3): 158-163.
[2] Catarci S et al (2016) Anesthetic management of urgent cesarean delivery in a parturient with acute malaria infection: Korean Journal of Anesthesiology 69(2):193-196 •

[3] Chen, R. et al (2013) Pregnant women's awareness and acceptance of epidural anesthesia and its influence on cesarean section rate control in China: A qualitative study. Health, 5, 1455-1460

[4] Chia, $\mathrm{H} \mathrm{H}$ et al (2015) A comparison of spinal and epidural anesthesia for cesarean section following epidural labor analgesia: A retrospective cohort study ActaAnaesthesiologicaTaiwanica 53 (2015) 7e11

[5] Dyer, R.A and James, M, F (2008) Maternal Hemodynamic Monitoring in Obstetric Anesthesia Anesthesiology 11 2008, Vol.109, 765-767

[6] Ginosar Y et al (2009) Pulse Oximeter Perfusion Index as an Early Indicator of Sympathectomy after Epidural Anesthesia ActaAnaesthesiol Scand. 2009 Sep;53(8):1018-26.

[7] Harpen S.H (2009) Conversion of epidural lab failure Journals Medicine \& Health BJA Volume 102, Issue 2 Pp. 240-243

[8] Heesen $M$ et al (2013). Is general anaesthesia for caesarean section associated with postpartum haemorrhage? Systematic review and metaanalysis.ActaAnaesthesiol Scand. 2013;57:1092-102.

[9] Hermanides, J et al Failed epidural: causes and management Br J Anaesth (2012) 109 (2): 144-154.

[10] Ho-Shiang Huang et al (2014) Perfusion Index Derived from a Pulse Oximeter Can Detect Changes in Peripheral Microcirculation during Uretero-RenalScopy Stone Manipulation (URS-SM) PLoS One. 2014; 9(12):

[11] Kathuria T.S \&Sapkal R (2016) Audit of caesarean section for non-progress of labor.Int $J$ ReprodContraceptObstet Gynecol. 2016 Apr;5(4):10021005

[12] Katircioglu K, et al (2008) A retrospective review of 34,109 epidural anesthetics for obstetric and gynecologic procedures at a single private hospital in Turkey. AnesthAnalg 2008;107:1742-5

[13] Khan, F. A et al (2006) Estimation of blood loss during Caesarean section: an audit.J Pak Med Assoc. 2006 Dec;56(12):572-5

[14] Lima, A.P.1 et al (2002) Use Of A Peripheral Perfusion Index Derived From The Pulse Oximetry Signal As A Noninvasive Indicator Of Perfusion Crit Care Med. 2002 Jun;30(6):1210-3.

[15] Lirk, P. (2014). Local anesthetics: New insights into risks and benefits The institutional Repository of the University of Amsterdam (UvA)

[16] Mupuri, R et al (2012) Predictive Model For The Inadequate Labour Epidural Analgesia: An Outcome of The Prospective Observational Study at University Women's Hospital M.E.J. Anesthesia 21 (5),

[17] Robert, P.S.I (2009) Epidural Anesthesia for Cesarean Delivery: Failure Rates Anesthesia \& Analgesia: April 2009 - Volume 108 - Issue 4 -p 1358 
International Journal of Trend in Scientific Research and Development (IJTSRD) @ www.ijtsrd.com eISSN: 2456-6470

[18] Royal College of Anaesthetists | Raising the Standard: a compendium of audit recipes | 3rd Edition 2012

[19] Samina Ismail et al (2015) Incidence of cesarean section and analysis of risk factors for failed conversion of labor epidural to surgical anesthesia: A prospective, observational study in a tertiary care center. Journal of Anaesthesiology Clinical Pharmacology Volume : 31 Issue : 4 pp: 535-541

[20] Sen, S (2016) Epidural Anaesthesia a Safe Option for Caesarean Section in Parturient with Severe Pulmonary Hypertension - A Case Report. J AnesthCrit Care Open Access 5(6): 00207

[21] Shibli KU \& Russell IF A survey of anaesthetic techniques used for caesarean section in the UK in 1997. Int J ObstetAnesth 2000;9:160-7

[22] Shin Y.D et al (2016) The effect of anaesthesia technique on caesarean section. Pak J Med Sci. 2016;32(1):147-150.

[23] Shiroyama K, et al (2003) Distance from the skin to epidural space at the first lumbar interspace in a Japanese obstetric population. Hiroshima J Med Sci. relief in Shanghai, China Social Science \&2003;52(2):27-2

[24] Simuyu, N (2015) Incidence Of Regional Anaesthesia Conversion To General Anaesthesia During Caeserean
Section At The Obstetric Theatre, Kenyatta National Hospital Retrieved, Dec $5^{\text {th }}, 2018$ from yahoo.com

[25] Speights, K (2017) Masimo Corporation Reports Solid Q4 With Growing Pulse Oximeter Sales Successful Epidural Blockade: A Prospective Study Anesthesiology 9 1999, Vol.91, 899

[26] Thangamuthu, A. et al (2013) Epidural failure rate using a standardiseddefinition. Int. J. Obstet. Anesthesia. $2013 ; 22: 310-315$.

[27] Toyama, S et al (2013) Perfusion index derived from a pulse oximeter can predict the incidence of hypotension during spinal anaesthesia for Caesarean deliveryBr J Anaesth. 2013 Aug;111(2):235-41.

[28] Wang, E (2017) Requests for cesarean deliveries: The politics of labor pain and pain Medicine Volume 173 January 2017, Pages 1-8

[29] World Federation of Societies of Anaesthesiologist (2001) Up Date in Anaesthesia SASA 2001/AAAC Congress Secretariat Department of Anaesthetics

[30] Zifeng X et al (2013) Assessment of Pulse Oximeter Perfusion Index in Pediatric Caudal Block under Basal Ketamine Anesthesia The Scientific World Journal Volume 2013, Article ID 183493, pp 6

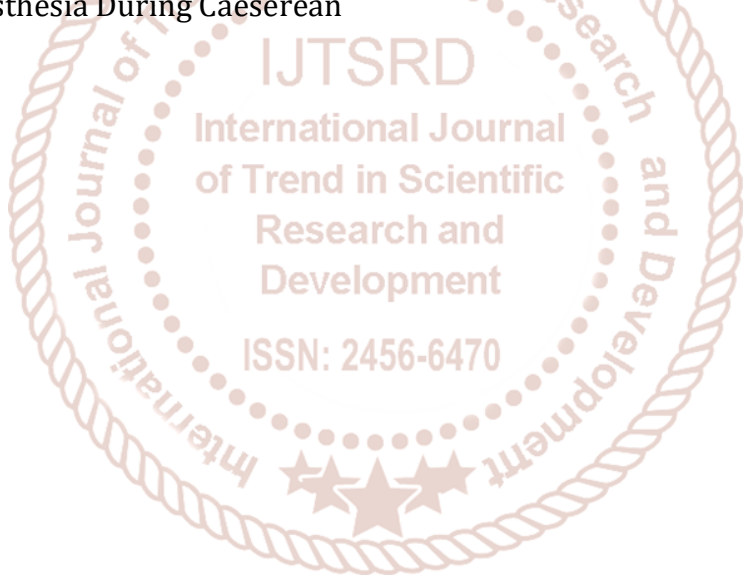

